\title{
Insulin resistance in obesity: body-weight or energy balance?
}

\author{
A R Assali', A Ganor, Y Beigel, Z Shafer, T Hershcovici \\ and $\mathbf{M}$ Fainaru
}

Lipid Research Laboratory, Department of Medicine A, Rabin Medical Center, Beilinson Campus, Petah Tiqva, Sackler Faculty of Medicine, Tel Aviv University, Tel Aviv, Israel

${ }^{1}$ Cardiology Department, Rabin Medical Center, Beilinson Campus, Petah Tiqva, Sackler Faculty of Medicine, Tel Aviv University, Tel Aviv, Israel

(Requests for offprints should be addressed to M Fainaru, Lipid Research Laboratory and Department of Medicine A, Rabin Medical Center, Beilinson Campus, Petah Tiqva 49 100, Israel; Email: mfainar@post.tau.ac.il)

\begin{abstract}
Weight reduction is recommended for the treatment of subjects with insulin resistance (IR) syndrome; however, the relative importance of the decrease in body fat or the negative energy balance achieved during a hypo-energetic diet in the improvement of this metabolic syndrome is still debated. Therefore, we undertook to study their relative impact on amelioration of the metabolic abnormalities associated with IR in obese subjects.

Twelve obese subjects (six males and six females, mean \pm S.D. body mass index $36 \cdot 1 \pm 4 \cdot 7 \mathrm{~kg} / \mathrm{m}^{2}$ ) aged $38-57$ years were investigated. During the first phase they were fed a hypo-energetic diet for 6 weeks (week 0-6). During the second phase, lasting 4 weeks (week 6-10) they consumed an iso-energetic diet. During the third phase (week 10-16) the subjects were put again on a hypo-energetic diet. Insulin sensitivity (SI) was assessed by an insulin-enhanced, frequently sampled i.v. glucose tolerance test with minimal model analysis. All subjects
\end{abstract}

reduced weight during both hypo-energetic periods: $5 \cdot 49 \pm 0.75$ and $2 \cdot 32 \pm 0 \cdot 37 \%$, means \pm s.E.M., $P<0 \cdot 005$, week $0-6$ and 10-16 respectively. One-third of this loss was achieved within the first week of each period. SI increased by $353 \pm 121$ and $147 \pm 38 \% \quad(P<0 \cdot 005)$, means \pm s.E.M., at the end of both hypo-energetic periods (week 6 vs 0 and 16 vs 10 respectively). Two-thirds of this improvement were observed within the first week of each period (week 1 vs 0 and 11 vs 10 respectively). During the

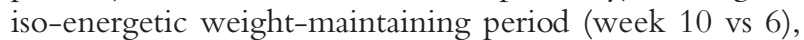
SI decreased by $43 \cdot 5 \pm 7 \cdot 9 \%(P<0 \cdot 002)$. Serum levels of leptin and triglyceride followed a similar pattern, but to a lesser extent.

It may be concluded that negative energy balance is more effective when compared with maintaining a stable lower weight in achieving an improvement in the metabolic parameters of the IR syndrome.

Journal of Endocrinology (2001) 171, 293-298

\section{Introduction}

Obesity threatens to become the 21st century's leading health problem (Rosenbaum et al. 1997). Several metabolic abnormalities are associated with obesity including: atherogenic dyslipidemia, elevated blood pressure, hypercoagulable state and insulin resistance (IR) (Bray 1996, Smith 1996). Most investigators believe that IR and the associated hyperinsulinemia are the cause of this metabolic syndrome, which is common in persons who develop premature coronary heart disease (Reaven 1988, Despres et al. 1996). IR is a heterogeneous syndrome with both genetic (Haffner et al. 1989, Dunaif 1997) and environmental (Moller \& Flier 1991, Facchini et al. 1992, Assali et al. 1999) factors playing key roles in its development. Although several reports have indicated that patients with IR are obese (particularly visceral obesity), it has been difficult to determine whether or not obesity is the primary abnormality in the pathogenesis of the syndrome
(Kannel et al. 1979, Henry et al. 1986, Hale et al. 1988, Reaven 1988, Franssila-Kallunki et al. 1992). Nagulesparan et al. (1980) demonstrated a positive correlation between IR and body weight; however, the amount of body fat is clearly not the sole determinant of IR. Mingrone et al. (1997) and unpublished data cited by Schwartz \& Seeley (1997) suggest that the improvement in IR is not related to the weight loss itself but to other changes that occur during this process. Weinstock et al. (1998) reported that the insulin levels in obese women who maintained $10 \%$ loss of their body weight returned to pretreatment levels. Furthermore, obese and lean subjects have a similar neuroendocrine response to active weight loss, and in both resumption of food intake reverses most of this effect, even if the lost weight is not regained (Schwartz \& Seeley 1997).

Since the centrally acting negative-feedback signals, leptin and insulin, are sensitive to both body fat mass and energy balance, we elected to study these and other 
metabolic variables associated with IR in obese subjects during two states of energy balance: hypo-energetic (active weight loss) and iso-energetic (at stable lower weight). Elucidation of their relative capacity to ameliorate the metabolic abnormalities associated with IR in obese subjects carries important therapeutic implications.

\section{Methods}

\section{Subjects}

Twelve healthy obese subjects, six men and six women, aged 38-57 years, with a body mass index (BMI) of $36.1 \pm 4.7 \mathrm{~kg} / \mathrm{m}^{2}$ were recruited by advertisement on the hospital bulletin board (Table 1). Because of the known effects of the menstrual cycle on plasma lipids and insulin sensitivity (SI) (Jones et al. 1988, Valdes \& Elkind-Hirsch 1991), only menopausal women were included. None had a history of cancer, heart, liver, kidney, endocrine, blood, lung, gastrointestinal and neurologic disease, nor detected abnormalities on physical examination and routine laboratory testing. All subjects were normotensive (blood pressure less than $140 / 90 \mathrm{mmHg}$ ), took no regular medications nor used medications known to affect weight or energy expenditure (e.g. hormonal replacement therapy, thyroid hormones or anorexigenic agents). The study had been approved by the hospital Ethics Committee and all subjects signed an informed consent.

\section{Study protocol}

The subjects were asked to maintain their usual physical activity, food intake, smoking habits and daily routine. After the initial workup and 4 weeks of weight stabilization, the subjects were randomly prescribed one of two hypo-energetic diets: low calorie diets (LCD) or very low calorie diets (VLCD) (one-third and two-thirds deficit of habitual energy intake respectively), consisting of 3350 $11300 \mathrm{~kJ} /$ day (50-55\% carbohydrate, 30\% fat, 15-20\% protein and $<300 \mathrm{mg}$ cholesterol/day), divided into four meals, for 6 weeks (first phase: week 0-6). The second phase consisted of 4 weeks (week 6-10) of a weightmaintaining iso-energetic diet. During the third phase (week 10-16) the subjects consumed the alternate hypoenergetic diet to achieve a second phase of active weight loss (those who were started on LCD were switched to VLCD and vice versa). Compliance with the study protocol and dietary habits were confirmed by weekly interviews and dietary recalls. All subjects maintained their daily routine and did not change their smoking habits during the entire study period. None of the subjects was taking part in physical fitness programs.

The subjects were studied at baseline (week 0); after 1 week (end of week 1) and at the end of the first period (end of week 6) of the hypo-energetic diet (LCD or
VLCD); after 4 weeks of the iso-energetic diet (end of week 10); after 1 week (end of week 11) and at the end (week 16) of the second (alternate VLCD or LCD) hypo-energetic diet (end of week 16). At each of these visits, conducted at $0800 \mathrm{~h}$, after $12 \mathrm{~h}$ overnight fast, the subjects were weighed, physically examined, blood withdrawn and the i.v. glucose tolerance test performed.

\section{Measurement and analysis}

Plasma cholesterol, triglyceride, and high-density lipoprotein (HDL) levels were determined by enzymatic methods (Boehringer, Mannheim, Germany). Plasma lipoproteins were determined by $\beta$-quantification. The SI-index was assessed by an insulin-enhanced, frequently sampled i.v. glucose tolerance test with minimal model analysis (Welch et al. 1990). In brief, after a $12 \mathrm{~h}$ overnight fast and $30 \mathrm{~min}$ recumbence, i.v. lines were inserted into the antecubital veins, one for blood sampling and one for glucose and insulin administration. Glucose $(0.3 \mathrm{~g} / \mathrm{kg})$ and insulin $(0.03 \mathrm{U} / \mathrm{kg})$ were injected i.v. at 0 and $20 \mathrm{~min}$ respectively, and blood samples for glucose and insulin determination were collected at $-5,-1,2,4,6,8,10$, $12,14,16,19,22,23,25,27,30,40,50,90,120$ and $180 \mathrm{~min}$. Blood glucose was determined by glucoseoxidase (Boehringer), serum insulin by RIA (Sorin, Biomedica, Sallugia, Italy) and leptin by RIA (Linco Research Inc., St Charles, MO, USA).

\section{Data analysis}

Data are presented as means \pm S.D. or means \pm S.E.M. Because of the large variability in the baseline values for anthropometric and metabolic parameters (Table 1), we elected to compute for each individual the percent differences from baseline values $(\Delta)$ and calculate their means and trends. As we observed no statistically significant differences between the effects of the two hypo-energetic diets (LCD and VLCD) on the studied metabolic parameters during the entire study $(P>0.5)$, and in order to simplify the presentation, we elected to pool the data. We estimated the significance of the observed differences between men and women, and within periods, by Student's $t$-test for unpaired and paired data respectively. We used repeated measures ANOVA to compare different periods and alternate diets, and Pearson correlation coefficient to study the degree of association between changes in SI and weight. $P \leq 0.05$ was considered significant.

\section{Results}

The baseline characteristics of the studied subjects are detailed in Table 1. The women recruited for this study were 10 years older than the men, to avoid the putative 
Table 1 Baseline characteristics of the studied subjects (means \pm S.D. (range)

\begin{tabular}{|c|c|c|c|}
\hline & $\begin{array}{l}\text { Males } \\
(n=6)\end{array}$ & $\begin{array}{l}\text { Females } \\
(n=6)\end{array}$ & $\begin{array}{l}\text { Total } \\
(n=12)\end{array}$ \\
\hline Age (years) & $\begin{array}{l}44 \cdot 6 \pm 5 \cdot 2 \\
(38-46)\end{array}$ & $\begin{array}{l}54 \cdot 0 \pm 2 \cdot 8 \\
(50-57)\end{array}$ & $49 \cdot 7 \pm 6 \cdot 2^{*}$ \\
\hline Body weight (kg) & $\begin{array}{l}109 \cdot 3 \pm 22 \cdot 4 \\
(91-149)\end{array}$ & $\begin{array}{l}95 \cdot 1 \pm 10 \cdot 5 \\
(81-107)\end{array}$ & $102 \cdot 2 \pm 18 \cdot 3$ \\
\hline Height $(\mathrm{cm})$ & $\begin{array}{l}175 \cdot 6 \pm 8 \cdot 8 \\
(163-190)\end{array}$ & $\begin{array}{l}160 \cdot 7 \pm 3 \cdot 1 \\
(158-165)\end{array}$ & $168 \cdot 1 \pm 10 \cdot 0^{*}$ \\
\hline BMI $\left(\mathrm{kg} / \mathrm{m}^{2}\right)$ & $\begin{array}{r}35 \cdot 2 \pm 4 \cdot 6 \\
(31 \cdot 5-41 \cdot 3)\end{array}$ & $\begin{array}{r}36 \cdot 9 \pm 5 \cdot 1 \\
(29 \cdot 9-43 \cdot 0)\end{array}$ & $36 \cdot 1 \pm 4 \cdot 7$ \\
\hline Fasting glucose $(\mathrm{mmol} / \mathrm{l})$ & $\begin{array}{c}5 \cdot 33 \pm 0 \cdot 41 \\
(4 \cdot 89-5 \cdot 94)\end{array}$ & $\begin{array}{c}5 \cdot 55 \pm 0 \cdot 66 \\
(4 \cdot 89-6 \cdot 77)\end{array}$ & $5 \cdot 45 \pm 0 \cdot 54$ \\
\hline Leptin (ng/ml) & $\begin{array}{l}13 \cdot 9 \pm 6 \cdot 6 \\
(6 \cdot 5-21 \cdot 2)\end{array}$ & $\begin{array}{r}31 \cdot 3 \pm 8 \cdot 3 \\
(19 \cdot 8-42 \cdot 4)\end{array}$ & $22 \cdot 6 \pm 11 \cdot 6^{*}$ \\
\hline Fasting insulin (pmol/l) & $\begin{array}{c}118 \pm 74 \\
(65-260)\end{array}$ & $\begin{array}{c}111 \pm 52 \\
(57-197)\end{array}$ & $114 \pm 61$ \\
\hline $\begin{array}{l}\text { Insulin sensitivity index } \\
\left(10^{-4} \times \mathrm{min}^{-1} / \mu \mathrm{U} \text { per } \mathrm{ml}\right) \\
\text { Cholesterol }(\mathrm{mmol} / \mathrm{l}\end{array}$ & $\begin{array}{l}1 \cdot 04 \pm 1 \cdot 15 \\
(0 \cdot 05-2 \cdot 3)\end{array}$ & $\begin{array}{l}1 \cdot 02 \pm 1 \cdot 80 \\
(0 \cdot 05-4 \cdot 4)\end{array}$ & $1 \cdot 03 \pm 1 \cdot 44$ \\
\hline Total & $\begin{array}{c}5 \cdot 95 \pm 1 \cdot 04 \\
(4 \cdot 89-7 \cdot 16)\end{array}$ & $\begin{array}{c}6 \cdot 32 \pm 0.93 \\
(4 \cdot 94-7 \cdot 68)\end{array}$ & $6 \cdot 14 \pm 0 \cdot 96$ \\
\hline VLDL & $\begin{array}{l}0 \cdot 83 \pm 0 \cdot 26 \\
(0 \cdot 59-1 \cdot 27)\end{array}$ & $\begin{array}{l}1 \cdot 00 \pm 0.45 \\
(0 \cdot 44-1 \cdot 66)\end{array}$ & $0 \cdot 91 \pm 0 \cdot 36$ \\
\hline LDL & $\begin{array}{l}3 \cdot 61 \pm 1 \cdot 06 \\
(2 \cdot 22-4 \cdot 78)\end{array}$ & $\begin{array}{l}3.95 \pm 0.77 \\
(2 \cdot 97-5 \cdot 09)\end{array}$ & $3 \cdot 78 \pm 0 \cdot 90$ \\
\hline $\mathrm{HDL}$ & $\begin{array}{l}1 \cdot 17 \pm 0 \cdot 13 \\
(0 \cdot 96-1 \cdot 27)\end{array}$ & $\begin{array}{l}1 \cdot 28 \pm 0.34 \\
(0.93-1.89)\end{array}$ & $1 \cdot 22 \pm 0 \cdot 25$ \\
\hline Triglyceride (mmol/l) & $\begin{array}{c}2 \cdot 56 \pm 0 \cdot 62 \\
(2 \cdot 07-3 \cdot 73)\end{array}$ & $\begin{array}{l}2 \cdot 38 \pm 0 \cdot 96 \\
(1 \cdot 59-3 \cdot 61)\end{array}$ & $2 \cdot 47 \pm 0 \cdot 75$ \\
\hline
\end{tabular}

${ }^{*} P<0 \cdot 05$, difference between males and females by unpaired Student's $t$-test.

effect of the menstrual cycle on studied metabolic parameters. Their average weight and height were lower, but their BMI was similar to those of the men. The baseline metabolic values besides those of leptin (which was more than 2-fold in women) were similar in both genders.

\section{Body weight}

All subjects lost weight during the study, with an average of $8.7 \mathrm{~kg}(P<0 \cdot 05)$. Men and women showed similar rates during all periods $(P>0.5$ (not shown)). Although the subjects starting on a VLCD regimen showed a tendency for a higher rate in weight reduction when compared with the subjects starting on an LCD, $2 \cdot 19$ vs $1 \cdot 43 \%$ within the first week (week $0-1$ ), 6.58 vs $4.55 \%$ during the first hypo-energetic period (week $0-6$ ) and $9 \cdot 40$ vs $8 \cdot 53 \%$ during the whole study (week 0-16) (percent of their initial body weight respectively), these differences did not reach statistical significance $(P>0 \cdot 5)$.

The body weight of the entire group was reduced by an average of $5 \cdot 49 \pm 0 \cdot 75 \%$, means \pm s.E.M., during the first hypo-energetic period (week 0-6, from $102 \cdot 2 \pm 5 \cdot 3$ to $96 \cdot 5 \pm 5 \cdot 1 \mathrm{~kg}, P=0 \cdot 003)$ and by $2 \cdot 32 \pm 0 \cdot 37 \%$ during the second hypo-energetic period (week 10-16, from
$95 \cdot 7 \pm 5 \cdot 2$ to $93 \cdot 5 \pm 5 \cdot 1 \mathrm{~kg}, P=0 \cdot 001)$. One-third of this weight reduction was observed during the first week of these periods (week 1 and 11) (Table 2 and Fig. 1). Although the subjects were encouraged to consume an iso-energetic diet during the interim iso-energetic period (week 6-10), most continued to lose weight, although at a reduced rate, with an average of $0.91 \pm 0.42 \%$ $(96.5 \pm 5.1$ to $95.7 \pm 5.2 \mathrm{~kg}, \quad P=0.037)$ during these 4 weeks (Table 2).

\section{SI}

Fasting serum glucose and insulin did not change significantly during the entire study (Table 2). The SI-index increased by $475 \pm 196 \%$ during the 16 weeks of study, from $1.03 \pm 0.43$ to $4.78 \pm 1.06\left(10^{-4} \times \mathrm{min}^{-1} / \mu \mathrm{U}\right.$ per $\mathrm{ml})$, means \pm S.E.M. $(P<0 \cdot 005)$. The increase in SI-index was $353 \pm 121 \%$ at the end of the first hypo-energetic period (week 0-6, from $1.03 \pm 0.43$ to $3.57 \pm 0.58$ $\left(10^{-4} \times \min ^{-1} / \mu \mathrm{U}\right.$ per $\left.\left.\mathrm{ml}\right), P=0 \cdot 0017\right)$, and by $147 \pm$ $38 \%(P=0.002)$ by the end of the second hypo-energetic period (week 10-16, from $1.96 \pm 0.50$ to $4.78 \pm 1.06$ $\left(10^{-4} \times \mathrm{min}^{-1} / \mu \mathrm{U}\right.$ per $\left.\left.\mathrm{ml}\right), P=0 \cdot 0016\right)$. Two-thirds of this increase in the SI-index were observed during the first week of each hypo-energetic period (week 1 and 11) 
Table 2 Changes in studied parameters during the study expressed as $\Delta \%$ during each period $(n=12)$. The first hypo-energetic dietary period (VLCD or LCD) lasted for 6 weeks $(0-6)$, followed by 4 weeks $(6-10)$ of iso-energetic intake and a second period of hypo-energetic dietary intake (LCD or VLCD) (weeks 10-16). Blood samples and i.v. glucose tolerance tests were obtained at the designated times. Values for each individual were calculated as $\Delta \%$ (i.e. for period $0-1$ ((value for week $1-$ value for week 0 )/value for period 0). These values were pooled for the whole group and expressed as means \pm S.E.M.

\begin{tabular}{|c|c|c|c|c|c|}
\hline & \multicolumn{2}{|l|}{ Hypo-energetic } & \multirow{2}{*}{$\frac{\text { Iso-energetic }}{6-10 \text { weeks }}$} & \multicolumn{2}{|l|}{ Hypo-energetic } \\
\hline & $0-1$ weeks & $0-6$ weeks & & 10-11 weeks & 10-16 weeks \\
\hline Body weight & $-1 \cdot 81 \pm 0 \cdot 24^{* *}$ & $-5 \cdot 49 \pm 0.75^{\star *}$ & $-0.91 \pm 0.42^{\star *}$ & $-0.75 \pm 0.20^{*}$ & $-2 \cdot 32 \pm 0 \cdot 37^{\star \star *}$ \\
\hline Insulin & $+9 \cdot 3 \pm 12 \cdot 4$ & $0 \cdot 4 \pm 13 \cdot 7$ & $+4 \cdot 2 \pm 12 \cdot 1$ & $7 \cdot 1 \pm 8 \cdot 4$ & $+3 \cdot 2 \pm 7 \cdot 7$ \\
\hline Leptin & $-22 \cdot 0 \pm 3 \cdot 2^{* *}$ & $-37 \cdot 7 \pm 5 \cdot 1^{* *}$ & $+18 \cdot 6 \pm 14.9$ & $-3 \cdot 3 \pm 8 \cdot 6$ & $+4.5 \pm 16.5$ \\
\hline SI-index & $+219 \pm 63^{* *}$ & $+353 \pm 121^{* *}$ & $-44 \pm 8^{* *}$ & $+103 \pm 23^{* *}$ & $+147 \pm 38^{\star *}$ \\
\hline VLDL & $-19 \cdot 3 \pm 6 \cdot 4^{* *}$ & $-22 \cdot 5 \pm 7 \cdot 6^{*}$ & $-10 \cdot 7 \pm 7 \cdot 9$ & $+2 \cdot 3 \pm 8 \cdot 6$ & $+2 \cdot 3 \pm 11 \cdot 2$ \\
\hline $\mathrm{LDL}$ & $+5 \cdot 5 \pm 6 \cdot 2$ & $+3.5 \pm 8 \cdot 1$ & $+4 \cdot 5 \pm 6 \cdot 2$ & $+0 \cdot 6 \pm 4 \cdot 8$ & $-6 \cdot 6 \pm 4 \cdot 0$ \\
\hline $\mathrm{HDL}$ & $-9 \cdot 3 \pm 3 \cdot 5^{*}$ & $-5 \cdot 2 \pm 4 \cdot 5$ & $+4 \cdot 7 \pm 3 \cdot 7$ & $-0 \cdot 4 \pm 2 \cdot 1$ & $-0 \cdot 6 \pm 2 \cdot 4$ \\
\hline
\end{tabular}

The statistics reflects comparison of the absolute values within each designated period by paired two-tailed Student's test: ${ }^{*} P<0 \cdot 05,{ }^{* *} P<0 \cdot 005$.
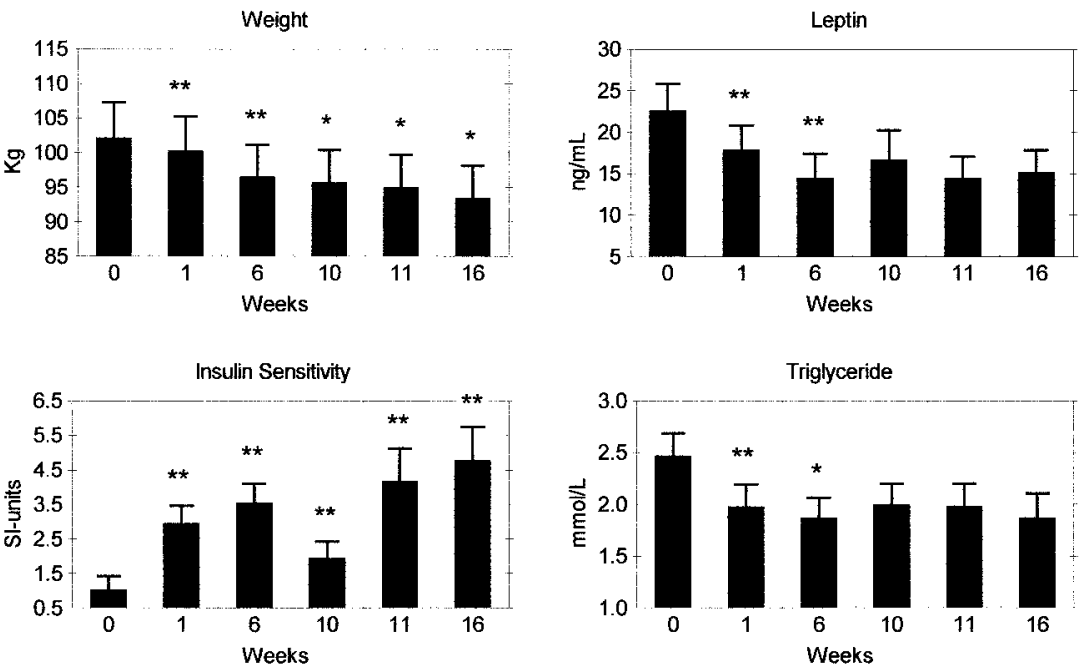

Figure 1 Changes of weight, SI (units $10^{-4} \times \mathrm{min}^{-1} / \mu \mathrm{U}$ per $\mathrm{ml}$ ), triglyceride and leptin during study periods. Values were pooled for the whole group and expressed as means \pm S.E.M., $n=12$. The statistics reflect comparison of the absolute values periods: $0-1$, $0-6,6-10,10-11$ and $10-16$ weeks by a paired two-tailed Student's $t$-test. ${ }^{*} P<0 \cdot 05$, $* * P<0 \cdot 005$.

(Table 2 and Fig. 1), while the body weight decreased by less than $2 \mathrm{~kg}$ (Fig. 1). During the iso-energetic period (week 6-10), although none of the subjects gained weight, we observed a decrease in the SI-index (from 3.57 \pm 0.57 to $1.96 \pm 0.50\left(10^{-4} \times \min ^{-1} / \mu \mathrm{U}\right.$ per $\left.\mathrm{ml}\right)$, week 6 and 10 respectively, $P=0 \cdot 0011$ ) (Table 2 , Fig. 1).

\section{Leptin}

Serum leptin levels decreased in both men and women during the study period by $33 \cdot 14 \pm 8 \cdot 04$ and $34 \cdot 24 \pm$ $5 \cdot 41 \%$, means \pm S.E.M. respectively (from $13 \cdot 87 \pm 1 \cdot 99$ to
$9 \cdot 43 \pm 1 \cdot 70$ and from $31 \cdot 28 \pm 2 \cdot 49$ to $20 \cdot 88 \pm 2 \cdot 83 \mathrm{ng} / \mathrm{ml}$ respectively, $P=0 \cdot 0014$, paired Student's $t$-test). The major part of this decrease occurred during the first hypo-energetic diet $(0-6$ weeks, from $13.87 \pm 1.99$ to $7.53 \pm 0.93$ and $31.28 \pm 2.49$ to $21.40 \pm 3.29 \mathrm{ng} / \mathrm{ml}$ in men and women respectively, $P=0.0007(42.3 \pm 3.9$ and $33 \cdot 0 \pm 5 \cdot 8 \%$ respectively). Fifty-eight percent of this decrease were observed during the first week (week 1) (Table 2 and Fig. 1). During the iso-energetic period (week 6-10), the leptin levels increased by $18 \%(P=0 \cdot 3)$, and tended to decrease during the second hypo-energetic period $(P=0 \cdot 4)$. 


\section{Plasma lipids and lipoproteins}

The changes observed in plasma total and low-density lipoprotein (LDL) cholesterol showed no consistent pattern and did not reach statistical significance (Table 2). Plasma HDL cholesterol showed a trend for decrease, reaching its lowest level within the first week of dieting (week 0-1), when it dropped from $1.22 \pm 0.08$ to $1 \cdot 10 \pm 0.06 \mathrm{mmol} / 1(P=0 \cdot 021)$, showing a tendency for increase thereafter (Table 2). Plasma triglyceride and very-low-density lipoprotein (VLDL) cholesterol decreased within the first week of the hypo-energetic diet (week $0-1)$ by $19 \cdot 5 \pm 6 \cdot 4 \%(P=0 \cdot 003)$ and $19 \cdot 3 \pm 6 \cdot 4 \%$ $(P=0.003)$ respectively. They continued to decrease during the next 5 weeks but increased thereafter (Table 2 and Fig. 1).

\section{Discussion}

The major observation of the present study indicates that energy restriction alone (i.e. negative energy balance) induces marked improvement in IR, serum leptin and triglyceride levels long before obese subjects lose a substantial amount of weight. Removal of the energy restriction even for a few weeks, while consuming an iso-energetic diet, leads to reversal of most of these beneficial effects, although the body weight did not increase. Beneficial effects of weight loss on glucose metabolism, plasma lipids and coronary artery disease risk in obese subjects have been well documented (Moller \& Flier 1991, Bray 1996, Mingrone et al. 1997, Rosenbaum et al. 1997). Such improvements, as shown also in our study, have been observed whether weight was lost with an LCD (4185-6280 kJ/day) or a VLCD (1675-3350 kJ/ day) diet (Wing et al. 1991, 1994).

Previous studies have focused on the role of loss in body fat during weight reduction but not on the role of energy balance. The glucose, insulin and lipoprotein abnormalities associated with obesity are attributed, in part, to overweight (Smith 1996, Rosenbaum et al. 1997); however, the results of the present study indicate that the decrease in both IR and serum leptin that accompany weight loss are related to the energy deficiency associated with active weight loss, and that this improvement is partially abolished during restoration of energy balance and stabilization at a lower weight.

Most of the observed improvement in SI is achieved during the first week of energy restriction, well before considerable weight is lost. During the first 6 weeks of study the subjects lost a mean of $5 \cdot 49 \%$ of their body weight and their SI improved by a mean of 353\%. Almost two-thirds of the improvement in SI had been achieved during the first week, when the mean weight loss was just $1-2 \mathrm{~kg}$ (one-third of the weight lost during the entire period). Similar findings were observed during the second phase of energy deficiency. These findings are consistent with previous studies (Wing et al. 1991, 1994, Weinstock et al. 1998) and indicate that the observed improvement in SI during weight loss is regulated by factors other than the adipose tissue mass.

It is highly unlikely that small changes in body weight could have been responsible for the profound decrease in IR, since caloric restriction alone is known to induce improvements in insulin and glucose levels, long before subjects have lost significant amounts of weight. Unlike previous studies, we observed that when the energy restriction is terminated, resumption of weightmaintaining food intake reverses most of the improvement in SI, even if the lost weight is not regained.

The occurrence of IR or its severity in obesity appears to be acquired to a large extent, since non-obese individuals develop IR upon weight gain (Campbell \& Gerich 1990, Caro 1991, Eckel 1992). Insulin-mediated glucose disposal drops by $30-40 \%$ when an individual is $40 \%$ over his ideal body weight (Golay et al. 1988, Pories et al. 1995). Previous studies have shown that weight reduction leads to permanent improvement in glucose tolerance and increased peripheral sensitivity to insulin action in obese subjects (Henry et al. 1986, Hale et al. 1988, FranssilaKallunki et al. 1992) and can restore fertility in obese women with polycystic ovary syndrome (Kiddy et al. 1992). Recently (Schwartz \& Seeley 1997) it was suggested that the amount of body fat is not the sole determinant of the neuroendocrine response to weight loss. This response, which includes lowering of insulin and leptin, is sensitive to both fat stores and energy balance. Hence it was suggested that active weight loss (i.e. negative energy balance) lowers the concentration of these hormones to values well below those observed during the weight-maintenance phase after weight reduction has been achieved when the adipose mass did not increase.

What could have been responsible for the rapid decrease in IR, observed promptly after initiating the negative energy balance? A definitive answer to this question is presently not available. It has been shown that excessive release of free fatty acids and glycerol from adipocytes into the circulation in the obese state is one of the major factors responsible for IR (Ferraninni et al. 1983, Svedberg et al. 1991). The increase in supply of free fatty acids from an enlarged fat mass leads to both an increase in oxidation of lipids, and through activation of the glucose-free fatty acid cycle (Randle et al. 1963, Bonadonna \& Bonora 1997, McGarry \& Dobbins 1999), to a decrease in the oxidation of glucose. Reversal of this cycle improves SI (Randle $e t$ al. 1963, Franssila-Kallunki et al. 1992). It is conceivable that the rapid and substantial reduction in IR within the first week of a hypo-energetic diet as observed in our study, is the result of the normalization of substrate oxidation, rather than a reduction in body fat mass.

Our study has several limitations. First we studied a small number of patients, but the prospective design resulted in consistent and significant results. The second is 
that we failed to maintain a stable weight during the second phase (iso-energetic) of the study in all subjects. Although it was difficult for the subjects to avoid further weight reduction, we have observed reversal in the trend of amelioration in IR, leptin and triglyceride levels.

It may thus be concluded that negative energy balance, induced by a hypo-energetic diet, has beneficial effects in the IR syndrome before a significant reduction in body weight. Corroboration of these finding in larger groups of patients will improve our understanding of the mechanism and treatment of this devastating metabolic syndrome.

\section{Acknowledgements}

The study is part of the requirement for an MSc degree for A G, Sackler Faculty of Medicine, Tel Aviv University, Tel Aviv, Israel.

\section{References}

Assali A, Beigel Y, Schreibman R, Shafer Z \& Fainaru M 1999 Weight gain and insulin resistance during nicotine replacement therapy. Clinical Cardiology 22 357-360.

Bonadonna RC \& Bonora E 1997 Glucose and free fatty acid metabolism in human obesity: relationships to insulin resistance. Diabetes Reviews 5 21-51.

Bray GA 1996 Health hazards of obesity. Endocrinology and Metabolism Clinics of North America 25 907-919.

Campbell PJ \& Gerich JE 1990 Impact of obesity on insulin action in volunteers with normal glucose tolerance: demonstration of a threshold for the adverse effect of obesity. Journal of Clinical Endocrinology and Metabolism 70 1114-1118.

Caro JF 1991 Insulin resistance in obese and nonobese man. Journal of Clinical Endocrinology and Metabolism 73 691-695.

Despres JP, Lamarche B, Mauriege P, Cantin B, Dagenais GR, Moorjani S \& Lupien PJ 1996 Hyperinsulinemia as an independent risk factor for ischemic heart disease. New England Journal of Medicine 334 952-957.

Dunaif A 1997 Insulin resistance and the polycystic ovary syndrome: mechanism and implications for pathogenesis. Endocrine Reviews $\mathbf{1 8}$ 774-800.

Eckel RH 1992 Insulin resistance: an adaptation for weight maintenance. Lancet 340 1452-1453.

Facchini FS, Hollenbeck CB, Jeppesen J, Chen V-DI \& Reaven GM 1992 Insulin resistance and cigarette smoking. Lancet 339 $1128-1130$.

Ferraninni E, Barret EJ, Bevilacqua S \& DeFronzo RA 1983 Effects of fatty acids on glucose production and utilization in man. Journal of Clinical Investigation 72 1737-1747.

Franssila-Kallunki A, Rissanen A, Ekstrand A, Ollus A \& Groop L 1992 Effects of weight loss on substrate oxidation, energy expenditure, and insulin sensitivity in obese individuals. American Journal of Clinical Nutrition 55 356-361.

Golay A, Felber JP, Jequier E, DeFronzo RA \& Ferrannini E 1988 Metabolic basis of obesity and non-insulin dependent diabetes mellitus. Diabetes/Metabolism Reviews 4 727-747.

Haffner SM, Stern MP, Hazuda HP, Mitchel BD, Patterson JK \& Ferrannini E 1989 Parental history of diabetes is associated with increased cardiovascular risk factors. Arteriosclerosis 9 928-933.

Hale PJ, Singh BM, Crase J, Baddeley RM \& Nattrass M 1988 Following weight loss in massively obese patients correction of the insulin resistance of fat metabolism is delayed relative to improvement in carbohydrate metabolism. Metabolism 37 411-417.

Henry RR, Wallace P \& Olefsky JM 1986 Effects of weight loss on mechanisms of hyperglycemia in obese non-insulin-dependent diabetes mellitus. Diabetes 35 990-998.

Jones DY, Judd JT, Taylor PR, Campbell WS \& Nair PP 1988 Menstrual cycle effect on plasma lipids. Metabolism 37 1-2.

Kannel WB, Gordon T \& Castelli WP 1979 Obesity, lipids, and glucose intolerance: the Framingham Study. American Journal of Clinical Nutrition 32 1238-1245.

Kiddy DS, Hamilton-Fairley D, Bush A, Short F, Anyaoku V, Reed MJ \& Franks S 1992 Improvement in endocrine and ovarian function during dietary treatment of obese women with polycystic ovary syndrome. Clinical Endocrinology 36 105-111.

McGarry JD \& Dobbins RL 1999 Fatty acids, lipotoxicity and insulin secretion. Diabetologia 42 128-138.

Mingrone G, DeGaetano A, Greco AV, Capristo E, Benedetti G, Castagneto M \& Gasbarrini G 1997 Reversibility of insulin resistance in obese diabetic patients: role of plasma lipids. Diabetologia 40 599-605.

Moller DE \& Flier JS 1991 Insulin resistance-mechanisms, syndromes, and implications. New England Journal of Medicine 325 938-948.

Nagulesparan M, Savage PJ, Mott DM, Johnson GC, Unger RH \& Bennett PH 1980 Increased insulin resistance in obese, glucoseintolerant Southwestern American Indians: evidence for a defect not explained by obesity. Journal of Clinical Endocrinology and Metabolism 51 739-743.

Pories WJ, Swanson MS, MacDonald KG, Long SB, Morris PG, Brown BM, Barakat HA, deRamon RA, Israel G \& Dolezal JM 1995 Who would have thought it? An operation proves to be the most effective therapy for adult-onset diabetes mellitus. Annals of Surgery 222 339-352.

Randle PJ, Garland PB \& Newsholme EA 1963 The glucose fatty acid cycle: its role in insulin sensitivity and metabolic disturbances of diabetes mellitus. Lancet 1 785-789.

Reaven GM 1988 Role of insulin resistance in human disease. Diabetes 37 1595-1607.

Rosenbaum M, Leibel RL \& Hirsch J 1997 Obesity. New England Journal of Medicine 337 396-407.

Schwartz MW \& Seeley RJ 1997 Neuroendocrine responses to starvation and weight loss. New England Journal of Medicine 336 1802-1811.

Smith SR 1996 The endocrinology of obesity. Endocrinology and Metabolism Clinics of North America 25 921-942.

Svedberg J, Strombland G, Wirth A, Smith U \& Bjorntorp P 1991 Fatty acids in the portal vein of the rat regulate hepatic insulin clearance. Journal of Clinical Investigation 88 2054-2058.

Valdes CT \& Elkind-Hirsch KE 1991 Intravenous glucose tolerance test derived insulin sensitivity changes during the menstrual cycle. Journal of Clinical Endocrinology and Metabolism 72 642-646.

Weinstock RS, Dai H \& Wadden TA 1998 Diet and exercise in the treatment of obesity. Archives of Internal Medicine 158 2477-2483.

Welch S, Gebhart SSP, Bergman RN \& Phillips LS 1990 Minimal model analysis of intravenous glucose tolerance tests derived insulin sensitivity in diabetic subjects. Journal of Clinical Endocrinology and Metabolism 71 1508-1518.

Wing RR, Marcus MD, Salata R, Epstein LH, Miaskiewicz S \& Blair EH 1991 Effects of a very-low-calorie diet on long-term glycemic control in obese type 2 diabetic subjects. Archives of Internal Medicine 151 1334-1340.

Wing RR, Blair EH, Marcus MD, Epstein LH \& Harvey J 1994 Year-long weight loss treatment for obese patients with type 2 diabetes: dose including an intermittent very-low-calorie diet improve outcome? American Journal of Medicine 97 354-362.

Received 16 March 2001

Accepted 24 July 2001 